\title{
Computing the inverse of the neurophysiological spike-response
} transform

\author{
Vladimir Brezina*1, Estee Stern1, Keyla García-Crescioni², Mark W Miller ${ }^{2}$ \\ and Charles S Peskin ${ }^{3}$
}

\begin{abstract}
Address: ${ }^{1}$ Department of Neuroscience, Mount Sinai School of Medicine, New York, NY, USA, 2Institute of Neurobiology, University of Puerto Rico Medical Sciences Campus, San Juan, Puerto Rico and ${ }^{3}$ Courant Institute of Mathematical Sciences and Center for Neural Science, New York University, New York, NY, USA

Email: Vladimir Brezina* - vladimir.brezina@mssm.edu

* Corresponding author
\end{abstract}

from Eighteenth Annual Computational Neuroscience Meeting: CNS*2009

Berlin, Germany. 18-23 July 2009

Published: 13 July 2009

BMC Neuroscience 2009, 10(Suppl I):P92 doi:10.II86/I47I-2202-I0-SI-P92

This abstract is available from: http://www.biomedcentral.com/I47I-2202/I0/SI/P92

(c) 2009 Brezina et al; licensee BioMed Central Ltd.

Consider the transform from a discrete spike train to a continuous neurophysiological response such as postsynaptic membrane voltage or muscle contraction. Here we ask about the inverse of this transform: given the response, how can we estimate from it the spike train that produced it? A simple kernel-based model of such a transform is

$$
R(t)=\sum_{i: t-N_{K} \leq t_{i}<t} K\left(t-t_{i}\right) A\left(t_{i}\right),
$$

where $t$ is time (already discretized for practical computation, so that $t$ is the index of a series of time bins), $t_{i}$ is the time of spike $i, K$ is the single-spike response kernel of length $N_{K}$ time bins, $A$ is an amplitude that scales $K$ at each spike time, and $R$ is the overall response to the spike train. In previous work $[1,2]$, we developed a method to "decode" (1) to find, given the spike times and the response $R$, simultaneously both $K$ and $A$. If the spike train is unknown, a spike might hypothetically occur in each time bin $t^{\prime}$. In that case, (1) generalizes to the standard convolution

$$
R(t)=\sum_{t^{\prime}=t-N_{K}}^{t-1} K\left(t-t^{\prime}\right) A\left(t^{\prime}\right)=\sum_{n=1}^{N_{K}} K(n) A(t-n) .
$$

The inverse transform can then be computed using (1) or (2), depending on the circumstances, in at least two ways. If, perhaps from a previous decoding of (1) with a known spike train, we know $K$, we can use our decoding method, or another standard method, to solve (2) in one step to find from a novel $R(t)$ the corresponding $A(t)$. In datasets with relatively low noise and low spike density, the spikes can then be identified simply as occurring in time bins where $A(t) \neq 0$ or, in practice, where $A(t)$ exceeds some threshold. Otherwise, $A(t)$ still reflects the input presented by the spike train, albeit in a more diffuse way. A more challenging problem occurs if $K$ is unknown. Then we can decode (1) to find $K$ and $A$ as previously [1,2], except iteratively, starting with the assumption that each time bin contains a spike and progressively deleting spikes from those bins that have the smallest values of $A$. Figure 1 shows an example with synthetic data where this method simultaneously found $K$ and $A$, reconstructed $R$, and identified each spike in the train, perfectly. We have used these methods successfully with synthetic data and with the real transforms from motor neuron spikes to postsynaptic membrane voltage and muscle contractions in the cardiac system of the blue crab [3]. 

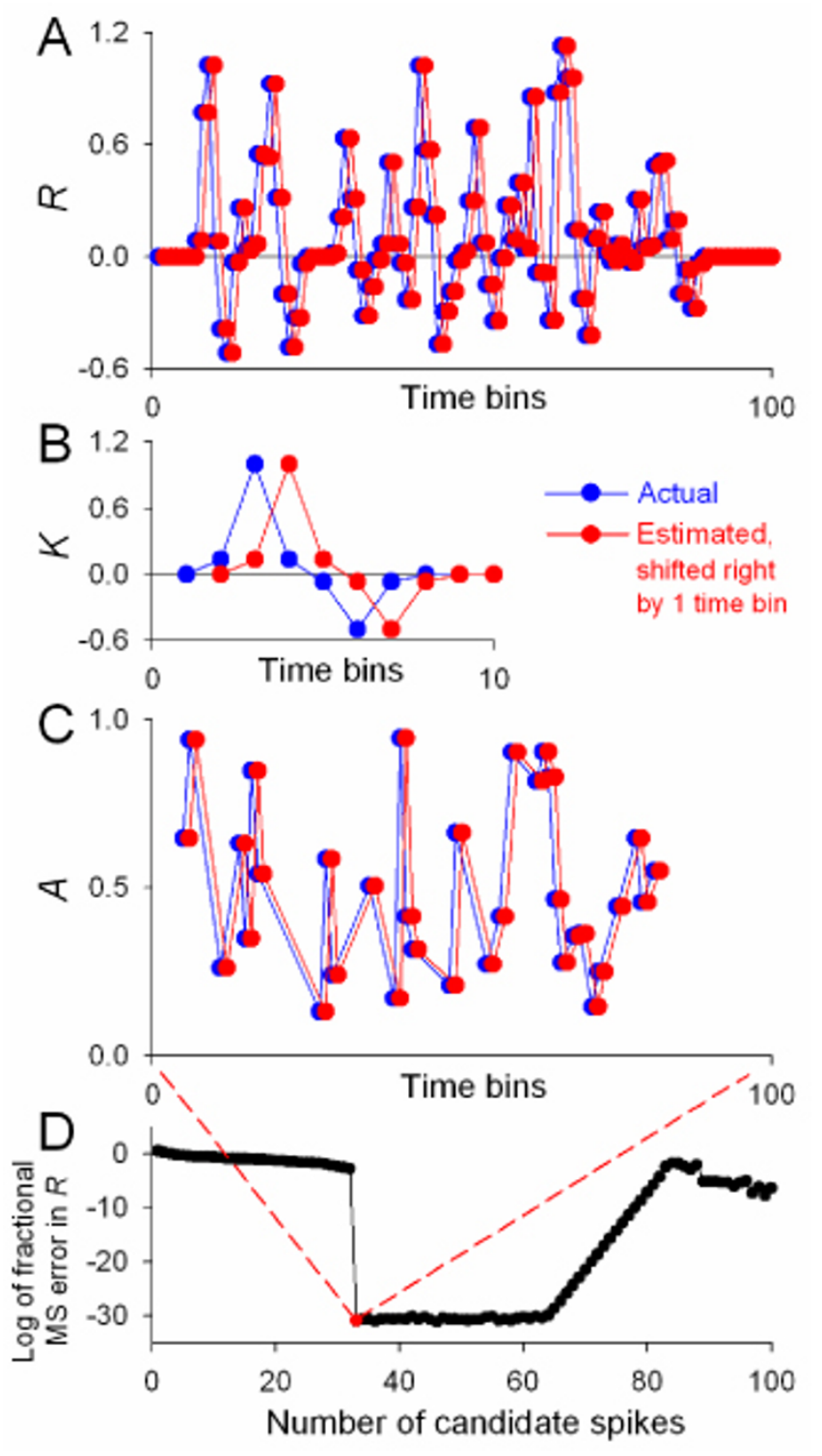

Figure I

Computation of the inverse transform illustrated with synthetic data. A-C, blue: $K$ and values of $A$ at 33 random spike times were used to construct the overall response $R$. A-C, red: the corresponding solutions found by the iterative decoding of $(I)$ with progressive deletion of candidate spikes. The corresponding blue and red points are in all cases identical; the red points have therefore been shifted right by I time bin for visibility. D: log of the fractional mean square error in the reconstruction of $R$.

\section{Acknowledgements}

Supported by NIH grants NS0580 I, NS4I497, GM08224, and RR0305I.

\section{References}

I. Stern E, Fort TJ, Miller MW, Peskin CS, Brezina V: Decoding neurophysiological responses to arbitrary spike trains. Soc Neurosci Abstr 2006. 491.7.

2. Stern E, Fort T], Miller MW, Peskin CS, Brezina V: Decoding modulation of the neuromuscular transform. Neurocomputing 2007, 70:1753-1758.

3. Stern E, Fort TJ, Miller MW, Peskin CS, Brezina V: Characterization of the crab cardiac neuromuscular transform. Soc Neurosci Abstr 2007. 536.I.
Publish with Biomed Central and every scientist can read your work free of charge

"BioMed Central will be the most significant development for disseminating the results of biomedical research in our lifetime. "

Sir Paul Nurse, Cancer Research UK

Your research papers will be:

- available free of charge to the entire biomedical community

- peer reviewed and published immediately upon acceptance

- cited in PubMed and archived on PubMed Central

- yours - you keep the copyright

Submit your manuscript here:

http://www.biomedcentral.com/info/publishing_adv.asp 